\title{
NÍVEIS DE CASCA DE SOJA EM RAÇÕES CONCENTRADAS PARA BEZERROS DE RAÇAS LEITEIRAS
}

\author{
Ivan Pedro de Oliveira Gomes ${ }^{1}$, André Thaler Neto', Lincoln Alves Medeiros', \\ Veridiane Orsolin ${ }^{1}$, Eduardo Peres Neto ${ }^{1}$, Claudio Eduard Neves Semmelmann ${ }^{1}$ \\ 1 UDESC \\ Correspondência: Ivan Gomes: a2ipog@cav.udesc.br
}

\begin{abstract}
RESUMO: O presente trabalho teve como objetivo avaliar quatro níveis de inclusão de casca de soja em rações concentradas para desaleitamento precoce de bezerros. Foram utilizados 36 bezerros, sendo 24 da raça Holandesa e 12 da raça Jersey, submetidos a quatro níveis de casca de soja (0, 15,30 e $45 \%$ ) adicionados em rações concentradas à base de milho, farelo de soja, palatabilizante e núcleo mineral, com $20 \%$ de proteína bruta. A duração do experimento foi de 16 semanas, considerando-se as fases de aleitamento (1-8 semanas) e pós-aleitamento (9-16 semanas). Na fase de aleitamento os animais receberam $4,0 \mathrm{~kg}$ de leite/dia, distribuídos em duas vezes, concentrado e água fornecidos à vontade. Após o desaleitamento os animais foram alimentados com concentrado e água à vontade e feno de alfafa na proporção de $20 \%$ do concentrado. Avaliou-se peso vivo, ganho de peso, altura à cernelha e ganho em altura, consumo de concentrado e volumoso e conversão alimentar ( $\mathrm{kg}$ de MS ingerida / $\mathrm{kg}$ de ganho de peso). Os tratamentos não afetaram nenhuma das variáveis analisadas $(P>0,05)$. Concluiu-se que a casca de soja pode ser incluída em até $45 \%$ das rações concentradas para bezerros desaleitados com oito semanas de idade.
\end{abstract}

Palavras-chave: alimentação; consumo; desempenho

\section{BARK OF SOYBEAN LEVELS IN DIETS FOR CONCENTRATED BREEDS OF DAIRY CALVES}

\begin{abstract}
This study aimed to evaluate the effect of inclusion of soybean hulls in starter rations for early weaned dairy calves, through the avaliation of weight gain, feed intake and feed conversion. The study included 36 calves, 24 Holstein and 12 Jersey, under four levels of soybean hulls $(0,15$, 30 and $45 \%$ ) added to a calf starter containing corn, soybean meal, flavor agent, minerals and vitamins, with $20 \%$ crude protein. The experiment was carried out for 16 weeks, considering eight weeks for liquid feeding period and eight weeks post-weaning. The calves received $4.0 \mathrm{~kg}$ of whole milk fed twice daily. Calf starter and water was offered ad libitum. Post-weaning the calves were feed with calf starter, alfalfa hay and water until 16th week. liveweight, daily gain, milk intake, starter intake, hay intake and feed conversion were registered. Starter and hay offered and refused was weight daily. No significant difference were observed for any variables analyzed $(P>0.05)$. It was concluded that soyhulls can included until $45 \%$ in the calf starter ration for calves weaned at eight weeks.
\end{abstract}

Key Words: calf starter; intake; weight gain 


\section{INTRODUÇÃO}

A alimentação de bezerros, exclusivamente com leite, tende a retardar o desenvolvimento do rúmen do animal, enquanto que a utilização de alimentos sólidos, especialmente concentrados, promove 0 desenvolvimento precoce do rúmen. Por esta razão a utilização de concentrados é fundamental no desaleitamento precoce porque, além de acelerar o desenvolvimento funcional do rúmen, oferece a possibilidade de diminuir substancialmente 0 custo da alimentação, especialmente quando são utilizados subprodutos na dieta sólida.

A utilização de casca de grão de soja como alimento energético, tem se mostrado como uma opção viável de substituição ao milho, principalmente para bovinos, visando à diminuição do custo de produção. A casca do grão de soja é o tegumento do grão de soja que é separado do embrião na indústria. Apresenta em média, na matéria seca, $13,9 \%$ de PB, $60,3 \%$ de FDN, $44,6 \%$ de FDA, 2,5\% de lignina, 2,7\% de EE e $4,8 \%$ de MM (NRC, 2001). Apesar do elevado teor de fibra, a digestibilidade ruminal da FDN pode alcançar $95 \%$ (Stern \& Ziemer, 1993). Com isso o valor energético é elevado, alcançando entre 77 e $80 \%$ de NDT na MS (NRC, 1982; NRC, 1996), comparável á grãos de aveia, espigas de milho e polpa cítrica. Trata-se, portanto, de um alimento rico em fibra e, portanto pode substituir alimentos concentrados ricos em amido, como substituir parcialmente os volumosos em dietas para bovinos.

O uso da casca de soja (tegumento) em substituição ao grão de milho tem sido pesquisado em bovinos e ovinos. Devido às suas características nutricionais é considerado um importante ingrediente na formulação de dietas para vacas leiteiras de alta produção (Ipharraguerre e Clark, 2003). Trabalhando com novilhos Angus em confinamento, Mueller \& Boogs (2011) concluíram que a casca de soja pode substituir uma combinação de milho e farelo de soja como suplemento em dietas a base de silagem de aveia. No Brasil, Gomes (1998) comparou três níveis de substituição do milho pela casca de soja (0,50 e $100 \%)$, em dietas contendo de 30 a $70 \%$ de concentrados, não encontrando diferenças no ganho de peso e na conversão alimentar de novilhos confinados. Ezequiel et al. (2006b) também não observaram efeito da substituição do milho pela casca de soja sobre o ganho de peso e rendimento de carcaça de bovinos de corte confinados recebendo dietas com relação volumoso (bagaço de cana):concentrado de 39:61. Restle et al. (2004) estudaram a substituição do grão de sorgo por casca de soja nos níveis de $0,25,50,75$ e $100 \%$ em dietas com relação volumoso:concentrado de 60:40 para novilhos confinados dos 19 aos 23 meses de idade. Concluíram que as dietas contendo casca de soja proporcionaram melhores ganhos de peso e conversão alimentar em relação a dietas contendo somente sorgo. Para novilhos Nelores alimentados com casca de soja em substituição parcial $(70 \%)$ ao milho, tendo a silagem de milho como volumoso, não houve alteração do desempenho e do rendimento de carcaça (Ezequiel et al., 2006a). Santos et al. (2005) observaram que a suplementação de novilhas de corte com casca de soja proporcionou ganhos de peso similares à suplementação com milho, com escores de condição corporal mais elevados. Silva et al. (2002) em um estudo com novilhos Holandês $x$ Zebu observou que a substituição do milho por casca de soja não afetou a digestão da PB, FDN e FDA. Com vacas leiteiras confinadas, Pedroso et al. (2007) demonstraram que a inclusão em até $20 \%$ da MS da dieta, em substituição ao milho, não afetou o 
consumo de matéria seca, a produção e composição do leite, entretanto, aumentou linearmente a produção total de gordura e diminui a concentração de $\mathrm{N}$-uréico no leite. Por outro lado em um trabalho (Hill et al., 2008) o uso de $62,75 \%$ de casca de soja em um concentrado inicial para bezerros durante o período de 4 a 8 semanas provocou uma diminuição de $10 \%$ do ganho de peso diário e $8 \%$ na eficiência alimentar, sem afetar o consumo. Os mesmos autores compararam a inclusão de quatro níveis de substituição do milho por casca de soja $(0,14,28$ e $42 \%$ ) em bezerros de 8 a 12 semanas de idade, verificaram uma redução linear do ganho de peso diário e da eficiência alimentar, também sem alterar o consumo.

Devido à escassez de informações sobre a utilização de casca de soja em concentrados iniciais para bezerros de raças leiteiras, desenvolveu-se 0 presente trabalho. Assim sendo, o objetivo foi comparar a inclusão de quatro níveis de casca de soja $(0,15,30$ e $45 \%$ ) como componente de rações concentradas sobre o desempenho de bezerros de raças leiteiras, desaleitados com oito semanas de idade.

\section{MATERIAL E MÉTODOS}

O trabalho foi desenvolvido no Setor de Gado Leiteiro do Centro de Ciências Agro veterinárias da Universidade do Estado de Santa Catarina em Lages, SC. Foram utilizados 36 bezerros, sendo 24 da raça Holandesa e 12 da raça Jersey, submetidos a quatro tratamentos com diferentes níveis de casca de soja ( 0 , $15, \quad 30$ e 45\%) adicionados em concentrados à base de milho e farelo de soja, palatabilizante e núcleo de minerais e vitaminas (Tabela 1). A duração do experimento foi de 16 semanas, considerando-se as fases de aleitamento (1-8 semanas) e pós- aleitamento (9-16 semanas). Os animais foram alojados em bezerreiros com baias individuais de $1 \times 1,5 \mathrm{~m}$, com piso ripado de madeira. Todos os animais receberam colostro e leite de transição até sete dias de idade, sendo a seguir distribuídos nos tratamentos. Foram fornecidos $4,0 \mathrm{~kg}$ de leite por dia, em duas porções, até oito semanas de idade. Durante a fase de aleitamento os bezerros receberam concentrado e água à vontade. Após 0 aleitamento os animais receberam água, concentrado à vontade e feno de alfafa, na proporção de $20 \%$ do concentrado. Diariamente registrou-se o consumo de leite, do concentrado, feno e sobras de concentrado e feno. O peso vivo e altura da cernelha foram registrados semanalmente.

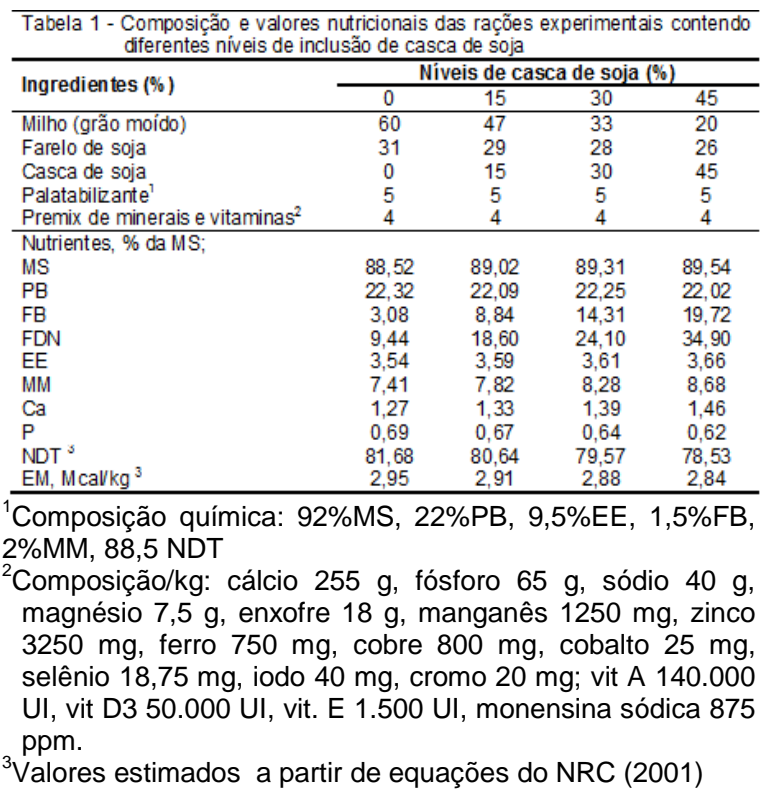

O delineamento experimental foi em blocos casualizados, com nove repetições por tratamento, sendo $6 \mathrm{com}$ bezerros Holandês e 3 com bezerros Jersey. Os dados obtidos foram submetidos à análise de variância utilizando-se o procedimento GLM, e efetuada análise de regressão utilizando-se o procedimento REG do pacote computacional SAS (SAS Institute, 1998) Os dados foram testados para normalidade dos resíduos pelo 
Teste de Shapiro-Wilk, conforme descrito por Santana e Ranal (2004).

\section{RESULTADOS E DISCUSSÃO}

Não foi observada interação entre grupamento genético (Jersey ou Holandês) e nível de inclusão de casca de soja no concentrado $(P>0,05)$ para nenhuma das variáveis estudadas. Devido a isto os resultados referem-se aos valores médios das duas raças.

Os valores médios de peso vivo, ganho de peso, altura na cernelha e ganho em altura dos bezerros durante os períodos experimentais encontramse na Tabela 2. Não foram observadas diferenças significativas entre os tratamentos para estas variáveis $(P>0,05)$ nos períodos de aleitamento e pós-aleitamento. Os coeficientes de regressão dos níveis de inclusão de casca de soja no concentrado sobre as variáveis dependentes estudadas, também não foram significativos $(P>0,05)$.

\begin{tabular}{|c|c|c|c|c|c|c|c|}
\hline \multirow{2}{*}{ Variáveis } & \multicolumn{4}{|c|}{ Níveis de casca de soja (\%) } & \multirow{2}{*}{$\mathrm{PDF}$} & \multirow{2}{*}{ EPM } & \multirow{2}{*}{$\begin{array}{l}\mathrm{CV} \\
(\%)\end{array}$} \\
\hline & 0 & 15 & 30 & 45 & & & \\
\hline Peso na $1^{2}$ semana & 39,17 & 37,68 & 39,00 & 37,71 & 0,826 & 0,74 & 11,51 \\
\hline Peso na $8^{2} \operatorname{sem} 2$ & 64,32 & 63,99 & 68,81 & 62,31 & 0,391 & 1,37 & 12,63 \\
\hline Peso na $16^{2}$ semana & 124,33 & 118,3 & 124,33 & 116,33 & 0,452 & 2,18 & 10,80 \\
\hline $\begin{array}{l}\text { Ganho de peso } 1-8 \\
\text { semanas (kg/dia) }\end{array}$ & 0,513 & 0,537 & 0,608 & 0,502 & 0,379 & 0,02 & 25,71 \\
\hline $\begin{array}{l}\text { Ganho de peso 9-16 } \\
\text { semanas (kg/dia) }\end{array}$ & 1,072 & 0,970 & 0,991 & 0,965 & 0,447 & 0,03 & 15,6 \\
\hline $\begin{array}{l}\text { Ganho de peso 1-16 } \\
\text { semanas (kg/dia) }\end{array}$ & 0,811 & 0,768 & 0,813 & 0,749 & 0,586 & 0,02 & 15,0 \\
\hline $\begin{array}{l}\text { Attura na } 1^{2} \text { semana } \\
\text { Altura na } 8^{2} \text { semana }\end{array}$ & $\begin{array}{l}70,00 \\
78,83\end{array}$ & $\begin{array}{l}69,83 \\
79,50\end{array}$ & $\begin{array}{l}70,11 \\
80,11\end{array}$ & $\begin{array}{l}69,50 \\
78,06\end{array}$ & $\begin{array}{l}0,965 \\
0,571\end{array}$ & $\begin{array}{l}0,44 \\
0,54\end{array}$ & $\begin{array}{l}3,8 \\
4,0\end{array}$ \\
\hline Altura na $16^{2}$ sem ana & 91,67 & 91,78 & 92,00 & 91,94 & 0,996 & 0,53 & 3,4 \\
\hline $\begin{array}{l}\text { Ganho de altura 1-8 } \\
\text { semanas }\end{array}$ & 8,83 & 9,67 & 10,00 & 8,56 & 0,756 & 0,54 & 35,0 \\
\hline $\begin{array}{l}\text { Ganho de altura 9-16 } \\
\text { semanas }\end{array}$ & 12,83 & 12,28 & 11,89 & 13,89 & 0,439 & 0,45 & 21,2 \\
\hline $\begin{array}{l}\text { Ganho de altura 1-16 } \\
\text { semanas }\end{array}$ & 21,67 & 21,94 & 21,89 & 22,44 & 0,978 & 0,62 & 16,9 \\
\hline
\end{tabular}

Os ganhos de peso observados no presente experimento superaram 0,5 $\mathrm{kg} / \mathrm{dia}$ durante o período de aleitamento e foram próximos a $1,0 \mathrm{~kg} / \mathrm{dia}$ nos animais desaleitados em todos os tratamentos, resultando em animais com pesos próximos a $120 \mathrm{~kg}$ as 16 semanas, condizentes com os valores médios publicados por Heinrichs e Losinger (1998) para a raça Holandesa nos Estados Unidos.
A inclusão de até $45 \%$ de casca de soja em concentrado inicial, substituindo principalmente 0 milho, proporcionou um adequado desempenho dos bezerros desaleitados precocemente e recriados até 12 semanas de idade. Outros autores também não encontraram influencia da substituição parcial ou total do milho por casca de soja sobre o desempenho animal em diferentes espécies e categorias animais, tais como novilhos confinados (Gomes, 1998), cordeiros terminados em confinamento (Santos et al., 2008) e vacas em lactação (Pedroso et al., 2007). Gomes (1998) observou que a inclusão da casca do grão de soja em dietas para bovinos confinados promoveu aumento na digestibilidade da fração fibrosa, ocasionando dessa forma um menor efeito associativo em relação às dietas contendo milho. Isto pode explicar o fato da substituição do milho pela casca de soja não ocasionar diferenças de desempenho, tanto em bovinos e ovinos, apesar do menor valor energético em relação ao milho, conforme valores publicados NRC (1982) e NRC (1996).

Não foram encontradas diferenças significativas entre os tratamentos $(P>0,05)$ para consumo de alimentos e conversão alimentar $(\mathrm{kg}$ alimento/kg ganho), conforme a Tabela 3. A média diária de consumo de concentrado concentrada durante 0 período de aleitamento foi de 0,525 $\mathrm{kg} /$ animal/dia, similar a 0,506 $\mathrm{kg} /$ animal/dia observado por Schalch et al. (2001) ao estudar a inclusão da polpa cítrica em níveis de $0,15,30$ e 45 $\%$ em rações para bezerros desaleitados com 70 dias de idade.

\begin{tabular}{|c|c|c|c|c|c|c|c|}
\hline \multirow[b]{2}{*}{ Variáveis } & \multirow{2}{*}{\multicolumn{4}{|c|}{ Niveis de casca de soja $(\%)$}} & \multirow[b]{2}{*}{$\operatorname{PrF}$} & \multirow[b]{2}{*}{ EPM } & \multirow{2}{*}{$\begin{array}{l}\text { CV } \\
(\%)\end{array}$} \\
\hline & & & & $\frac{a(\%)}{45}$ & & & \\
\hline $\begin{array}{l}\text { Consumo de concentrado } \\
1-8 \text { semanas }(\mathrm{kg} / \mathrm{dia})\end{array}$ & 0,494 & 0,437 & 0,614 & 0,418 & 0,178 & 0,07 & 50,6 \\
\hline $\begin{array}{l}\text { Consumo de concentrado } \\
\text { 9-16 semanas (kg/dia) }\end{array}$ & 2,633 & 2,513 & 2,827 & 2,421 & 0,166 & 0,05 & 15,3 \\
\hline $\begin{array}{l}\text { Consumo de concentrado } \\
1-16 \text { semanas }(\mathrm{kg} / \mathrm{dia})\end{array}$ & 1,634 & 1,544 & 1,793 & 1,486 & 0,371 & 0,05 & 18,5 \\
\hline $\begin{array}{l}\text { C.A. 1-8 semanas } \\
\text { C.A. } 9-16 \text { semanas }^{2}\end{array}$ & $\begin{array}{l}2,19 \\
2,89\end{array}$ & 1,76 & 1,83 & 1,87 & 0,220 & 0,07 & $\begin{array}{l}36,6 \\
16,7\end{array}$ \\
\hline C.A. $1-16$ semanas $^{3}$ & 2,65 & 2,59 & 2,75 & 2,59 & 0,347 & 0,04 & 13,7 \\
\hline
\end{tabular}


As informações científicas sobre a utilização de casca de soja em concentrado para bezerros são bastante limitadas e restritas a animais já desaleitados. Hill et al. (2008) observaram redução da média de ganho diário e da eficiência de ganho, com a substituição do milho pela casca de soja em concentrados para bezerras leiteiras após o desaleitamento. A alta taxa de inclusão de casca de soja (62,75\%) e o nível mais elevado de FDN (45,3\%) podem explicar a diferença entre estes trabalhos. Hill et al. (2008) também compararam rações contendo $0,14,28$ e $42 \%$ de casca de soja para bezerros com 8 a 9 semanas de idade $(73,1 \pm 3,1$ $\mathrm{kg})$ no início do experimento. Encontraram um decréscimo de $14 \%$ no ganho diário de peso com a inclusão de $42 \%$ de casca de soja em relação ao nível 0 \%. A eficiência do ganho também tendeu a decrescer de forma linear $(P>0,09)$. Não houve diferença para as variáveis ganho em altura e consumo de concentrado.

As rações com maiores níveis de inclusão de casca de soja (30 e 45\%) apresentaram níveis de FDN relativamente elevados (>20\%) sem comprometerem o consumo e o ganho de peso dos animais, mesmo no período de aleitamento. Coverdale et al. (2004) estudaram a inclusão de uma fonte de fibra (feno de gramínea) incorporado às rações peletizadas para bezerros leiteiros. Concluíram que a adição de até $15 \%$ de feno com adequado tamanho de partículas (8 a $19 \mathrm{~mm}$ ) promoveram um aumento no ganho de peso, consumo de ração na eficiência alimentar. Por outro lado, Hill et al. (2009) encontraram um efeito negativo da inclusão de forragem no desempenho de bezerros desaleitados. Em todos os experimentos o uso de rações mais fibrosas não resultou em aumento da incidência de diarréias e no escore fecal. (Coverdale et al., 2004; Hill et al., 2008; Hill et al., 2009). É necessário ressaltar que no período de aleitamento não foi usado alimento volumoso, e no período pós-aleitamento o feno de alfafa foi incluído no nível fixo de $20 \%$ para todos os tratamentos. Neste aspecto, vários autores destacam a necessidade de mais estudos sobre o nível, tipo e forma física de fibra a ser incorporada nas rações para bezerros desmamados precocemente.

Os valores dos coeficientes de variação das variáveis ganho de peso e consumo de concentrado, de 25,7\% e de $50,6 \%$, respectivamente, durante o período de aleitamento, porém são compatíveis com os valores encontrados na literatura. Kertz e Chester-Jones (2004) em uma revisão sobre 19 experimentos com bezerros e novilhas de raças leiteiras publicados no Journal of Dairy Science durante 5 anos (1998 a 2002), encontraram CV médio de $43 \%$ (20 a 190) e de $32 \%$ (19 a 60) para consumo de ração. Nestes experimentos os ganhos médios diários de peso foram de $0,44 \mathrm{~kg}(0,20$ a 0,90$)$ e o consumo médio de concentrado de $0,60 \mathrm{~kg}(0,28$ a 1,09). Os valores médios encontrados no presente experimento para o período de aleitamento (1-8 semanas) estão bastante próximos aos encontrados nesta revisão.

\section{CONCLUSÃO}

Conclui-se que a casca de soja pode ser incluída em até $45 \%$ nas rações concentradas para bezerros desaleitados com oito semanas de idade, sem afetar o ganho de peso, a altura na cernelha, o consumo e a conversão alimentar.

\section{REFERÊNCIAS}

COVERDALE, J.A.; TYLER, H.D.; QUIGLEY, J.D. et al. Effect of various levels of forage and form of diet on rumen development and growth in calves. Journal of Dairy Science, v.87,n.8, p.2554-2562, 2004. 
EZEQUIEL, J.B.; GALATI, R.L.; MENDES, A.R. et al. Desempenho e características de carcaça de bovinos Nelore em confinamento alimentados com bagaço de cana-de-açúcar e diferentes fontes energéticas. Revista Brasileira de Zootecnia, v.35, n.5, p.2050-2057, 2006a.

EZEQUIEL, J.; CRUZ E SILVA, O.; GALATI, R. Desempenho de novilhos Nelore alimentados com casca de soja ou farelo de gérmen de milho em substituição parcial ao milho moído. Revista Brasileira de Zootecnia, v.35, n.2, p569-575, 2006b.

GOMES, I.P.O. Substituição do milho pela casca de soja em dietas com diferentes proporções de de volumoso:concentrado para bovinos em confinamento. 1998. Jaboticabal, 84 p. Tese (Doutorado em Zootecnia) - Faculdade de Ciências Agrárias e Veterinárias, Universidade Estadual Paulista.

HEINRICHS, A.J.; LOSINGER, W.C. Growth of Holstein dairy heifers in the United states.

Journal of Animal Science, v.76, n.5, p.12541260, 1998.

HILL, T.M.; BATEMAN II, H.G.; ALDRICH, J.M. et al. Roughage diets fed to weaned dairy calves. The Professional Animal Scientist, v.25, n.2, p.283-288, 2009.

HILL, T.M.; BATEMAN II, H.G.; ALDRICH, J.M. et al. Effects of feeding different carbohydrate sources and amounts to young calves. Journal of Dairy Science, v.91, n.8, p.3128-3137, 2008.

IPHARRAGUERRE, I.R.; CLARK, J.H. Soyhulls as an alternative feed for lactating dairy cows: a review. Journal of Dairy Science, v.86, n.4, p.1052-1073, 2003.

KERTZ, A.F.; CHESTER-JONES, H. Guidelines for measuring and reporting calf and heifer experimental data. Journal of Dairy Science. v.87, n.11, p.3577-3580, 2004.

MUELLER, C.J.; BOGGS, D.L. Use of soybean hulls with or without corn by-product protein sources in feedlot backgrounding diets. The Professional Animal Scientist, v.27, n.3, p228234, 2011.

NRC - NATIONAL RESEARCH COUNCIL. United States - Canadian tables of feed composition. Washinton, D.C.: National Acadmies Press, 1982. 146p.

NRC - NATIONAL RESEARCH COUNCIL. Nutrient requeriments of beef cattle.

Washinton, D.C.: National Acadmies Press, 1996. 228p.

NRC - NATIONAL RESEARCH COUNCIL. Nutrient requeriments of dairy cattle. 7 . ed.
Washinton, D.C.: National Acadmies Press, 2001. 381p.

PEDROSO, A.M; SANTOS, F.A.P.; BITTAR, C.M.M. et al. Substituição do milho moído por casca de soja na ração de vacas leiteiras em confinamento. Revista Brasileira de Zootecnia, v.36, n.5, p.1651-1657, 2007.

RESTLE, J.; FATURI,C.; ALVES FILHO, D.C. et al. Substituição do grão de sorgo por casca de soja na dieta de novilhos terminados em confinamento. Revista Brasileira de Zootecnia, v.33, n.4, p.1009-1015, 2004.

SANTANA, D. G.; RANAL, M. A. Análise estatística. In: A. G. Ferreira e B. F. (ed.). Germinação - do básico ao aplicado. Porto Alegre: ArtMed . 2004, p.197-208.

SANTOS, D.T. dos; ROCHA, M.G. da; QUADROS, F.L.F. et al. Suplementos energéticos para recria de novilhas de corte em pastagens anuais: desempenho animal. Revista Brasileira de Zootecnia, v.34, n.1, p.209-219, 2005.

SANTOS, J.W. dos; CABRAL, L.S.; ZERVOUDAKIS J.T. et al. Casca de soja em dietas para ovinos. Revista Brasileira de Zootecnia, v.37, n.11, p.2049-2055, 2008.

SCHALCH, F.J.; SCHALCH, E.; ZANETTI, M.A. et al. Substituição do milho em grão moído pela polpa cítrica na desmama precoce de bezerros leiteiros. Revista Brasileira de Zootecnia, v.30, n.1, p.280-285, 2001.

SAS INSTITUTE. SAS/STAT, User's guide version 6.12. Cary: SAS Institute, 1998. 842 p.

SILVA, L.D.F. da.; EZEQUIEL, J.; AZEVEDO, P.S. et al. Digestão total e parcial de alguns componentes de dietas contendo diferentes níveis de casca de soja e fontes de nitrogênio, em bovinos. Revista Brasileira de Zootecnia, v.31, n.3, p. 1258-1268, 2002.

STERN, M.D.; ZIEMER, C.J. Consider value, cost when selecting nonforage fibre. Feedstuffs, v.65, n.2, p.14-17, 1993. 